\title{
Copper-64: a real theranostic agent
}

This article was published in the following Dove Press journal:

Drug Design, Development and Therapy

\author{
Bianca Gutfilen' \\ Sergio AL Souza' \\ Gianluca Valentini ${ }^{2}$ \\ 'Department of Radiology, School of \\ Medicine, Laboratório de Marcação \\ de Células e Moléculas (LMCM), \\ Universidade Federal do Rio de \\ Janeiro, Rio de Janeiro, Brazil; \\ ${ }^{2}$ Advanced Center Oncology Macerata \\ (ACOM), Montecosaro, Italy
}

\begin{abstract}
Ongoing studies of physiological and pathological processes have led to a corresponding need for new radiopharmaceuticals, especially when studies are limited by the absence of a particular radiolabeled target. Thus, the development of new radioactive tracers is highly relevant and can represent a significant contribution to efforts to elucidate important phenomena in biology. Currently, theranostics represents a new frontier in the fields of medicine and nuclear medicine, with the same compound being used for both diagnosis and treatment. In the human body, copper $(\mathrm{Cu})$ is the third most abundant metal and it plays a crucial role in many biological functions. Correspondingly, in various acquired and inherited pathological conditions, such as cancer and Alzheimer's disease, alterations in $\mathrm{Cu}$ levels have been found. Moreover, a wide spectrum of neurodegenerative disorders are associated with higher or lower levels of $\mathrm{Cu}$, as well as inappropriately bound or distributed levels of $\mathrm{Cu}$ in the brain. In human cells, the membrane protein, $\mathrm{hCtr} 1$, binds $\mathrm{Cu}$ in its $\mathrm{Cu}(\mathrm{I})$ oxidation state in an energy-dependent manner. Copper-64 $\left({ }^{64} \mathrm{Cu}\right)$ is a cyclotron-produced radionuclide that has exhibited physical properties that are complementary for diagnosis and/or therapeutic purposes. To date, very few reports have described the clinical development of ${ }^{64} \mathrm{Cu}$ as a radiotracer for cancer imaging. In this review, we highlight recent insights in our understanding and use of ${ }^{64} \mathrm{CuCl}_{2}$ as a theranostic agent for various types of tumors. To the best of our knowledge, no adverse effects or clinically observable pharmacological effects have been described for ${ }^{64} \mathrm{CuCl}_{2}$ in the literature. Thus, ${ }^{64} \mathrm{Cu}$ represents a revolutionary radiopharmaceutical for positron emission tomography imaging and opens a new era in the theranostic field.
\end{abstract}

Keywords: Copper-64, theranostic, cancer, radiopharmaceutical, PET

After iron and zinc, copper $(\mathrm{Cu})$ is the third most abundant trace transition metal in the human body with a normal content of $1.4-2.1 \mathrm{mg} / \mathrm{kg} .{ }^{1-3}$ Moreover, similar to $\mathrm{Fe}$ and $\mathrm{Zn}, \mathrm{Cu}$ ions are essential for various biological processes, which makes $\mathrm{Cu}$ indispensable for life. ${ }^{1,4,5}$ The biological role of $\mathrm{Cu}$ coincides with the establishment of an oxygen atmosphere $\sim 1.7$ billion years ago. $\mathrm{O}_{2}$ facilitates the oxidation of insoluble $\mathrm{Cu}(\mathrm{I})$ to a more soluble form, $\mathrm{Cu}(\mathrm{II})$, which is also more bioavailable. An $\mathrm{O}_{2}$ atmosphere also led to the requirement for redox active metals with potentials ranging from 0 to $800 \mathrm{mV}$. Thus, for many proteins that react with $\mathrm{O}_{2}, \mathrm{Cu}$ is a key component. ${ }^{6}$

In the past few decades, great advances have been made in our understanding of the molecular and cellular mechanisms that mediate $\mathrm{Cu}$ homeostasis. More recently, $\mathrm{Cu}$ has been shown to play a key role in healthy neuronal function. Meanwhile, anomalous $\mathrm{Cu}$ homeostasis has been detected in many important and common diseases such as Parkinson's disease, Alzheimer's disease, motor neuron diseases, amyotrophic lateral sclerosis, and prion disease. ${ }^{6-12}$ In Menkes and Wilson's diseases, systemic disproportions in $\mathrm{Cu}$ have also been observed, and these have been found to affect clinical 
and biochemical outcomes. ${ }^{6,11-14}$ For example, Camakaris et al detected resistance to $\mathrm{Cu}$ at the cellular level following amplification of the Menkes gene, and this was mediated via an increase in $\mathrm{Cu}$ efflux. ${ }^{15}$ This result supports a role for Menkes proteins to serve as $\mathrm{Cu}$ efflux proteins, and is also consistent with the identification of the Menkes protein as a member of the P-type ATPase family and the phenotype of cultured cells that express the Menkes protein. ${ }^{15}$

For good health, it is important for $\mathrm{Cu}$ ion homeostasis to be tightly regulated. It is estimated that the daily diet of a healthy adult includes $0.6-1.6 \mathrm{mg}$ of $\mathrm{Cu} .^{5,7,13}$ Conversely, it is hypothesized that $\mathrm{Cu}$ deficiency as a chronic dietary condition contributes to osteoporosis and cardiovascular diseases. ${ }^{7,13} \mathrm{Cu}$ imbalances have been identified in cancer patients, while $\mathrm{Cu}$ toxicity disorders and $\mathrm{Cu}$ deficiency can also be inherited or acquired.

$\mathrm{Cu}$ exists in two redox states relevant to biological systems, $\mathrm{Cu}^{+2}$ (cupric) and $\mathrm{Cu}^{+1}$ (cuprous). Many enzymatic systems need $\mathrm{Cu}$ as a cofactor, such as iron metabolism and respiratory oxidation. Cu's capacity to donate and accept electrons is also key to its role in neurotransmitter synthesis and pigment formation. ${ }^{12}$

$\mathrm{Cu}$ is transported across the plasma membrane of cells before becoming accessible in cellular compartments for incorporation into $\mathrm{Cu}$-dependent proteins. ${ }^{12,14,16,17}$ Studies of yeast cells were the first to identify the specific genes that encode the proteins responsible for $\mathrm{Cu}$ uptake. For example, two proteins that exhibit a high affinity for $\mathrm{Cu}$ uptake, $\mathrm{Ctr} 1$ and Ctr3, were originally characterized in Saccharomyces cerevisiae, ${ }^{14,16,17}$ while $\mathrm{Ctr} 4$ and $\mathrm{Ctr} 5$ were found to form heteromeric complexes in Schizosaccharomyces pombe. ${ }^{17}$ Subsequently, homology searches of databases and complementation studies of yeast mutants identified both mouse and human CTR1 homologs. ${ }^{16}$ In mammals, cellular import of $\mathrm{Cu}$ is primarily mediated via $\mathrm{Ctr} 1$ and $\mathrm{Ctr} 2$, and $\mathrm{Ctr} 1$ is the predominant transporter of dietary $\mathrm{Cu}$ from the intestinal lumen. ${ }^{12}$ Details regarding the mechanisms responsible for mediating $\mathrm{Cu}$ uptake by human cells were limited until various $\mathrm{Cu}$-binding proteins, referred to as $\mathrm{Cu}$ chaperone proteins, were identified. When concentrations of extracellular $\mathrm{Cu}$ are low and the amount of free intracellular $\mathrm{Cu}$ is negligible, copper chaperone for SOD1 (CCS), cytochrome c oxidase copper chaperone (COX17), and antioxidant protein (ATOX1) play key roles in adjusting Cu levels. Conversely, when concentrations of $\mathrm{Cu}$ are elevated, the roles of these three proteins appear to become diluted due to a greater role for non-specific $\mathrm{Cu}$-binding carriers. ${ }^{15}$ When $\mathrm{Cu}$ ions are in excess and need to be cleared from a biological system, a hepatobiliary route is preferred. For this process, $\mathrm{Cu}$ ions that are bound to plasma proteins, such as ceruloplasmin, transcuprein, and albumin, are carried to the cell surface. Once there, reductase enzymes reduce the $\mathrm{Cu}^{2+}$ ions to $\mathrm{Cu}^{+}$ ions prior to their uptake into cells. Reduced $\mathrm{Cu}^{+}$ions are subsequently transported across the cell membrane by the transmembrane protein, hCTR1, a 190-amino acid protein $(28 \mathrm{kDa})$ that has a high affinity for $\mathrm{Cu} .^{5,12}$

By the turn of the century, the role of systemic $\mathrm{Cu}$ homeostasis in both healthy and disease states had become more clear. With the subsequent development of $\mathrm{Cu}$ radionuclides, more localized detection of $\mathrm{Cu}$ in body liquids, tissues, and organs was achieved, and this provided more specific insights compared with the detection of overall systemic levels of $\mathrm{Cu} .{ }^{12}$ Currently, the available radioisotopes of $\mathrm{Cu}$ include ${ }^{60} \mathrm{Cu},{ }^{61} \mathrm{Cu},{ }^{62} \mathrm{Cu},{ }^{64} \mathrm{Cu}$, and ${ }^{67} \mathrm{Cu}$. The half-lives of these radioisotopes range from 9.8 minute to 61.9 hour, and this makes them compatible with radiotherapy and/or imaging protocols. ${ }^{18,19}$ In general, ${ }^{62} \mathrm{Cu}$ is used for diagnosis and ${ }^{64} \mathrm{Cu}$ is used for both diagnosis and therapy. Moreover, there is an improved availability of ${ }^{64} \mathrm{Cu}$ compared to ${ }^{67} \mathrm{Cu}$.

Only a few ${ }^{64} \mathrm{Cu}$ radioisotopes are able to be produced in a cyclotron or a nuclear reactor, ${ }^{1,5}$ and ${ }^{64} \mathrm{CuCl}_{2}$ is one of those compounds. In a cyclotron, the radionuclide, ${ }^{64} \mathrm{Cu}$, is produced in no-carrier-added state via a ${ }^{64} \mathrm{Ni}(\mathrm{p}, \mathrm{n}){ }^{64} \mathrm{Cu}$ reaction. ${ }^{16}$ The intermediate half-life of the resulting radionuclide is 12.7 hour and decay occurs via electron capture (44\%), $\beta^{+}$emission $(17 \%, 0.655 \mathrm{MeV})$, and $\beta$-emission (39\%, $0.573 \mathrm{MeV})$. Electron capture also leads to the release of Auger electrons, thereby facilitating its use for therapy when $\mathrm{Cu}$ localizes to cell nuclei. ${ }^{12,20}$ Trace amounts of $\beta^{+}$and $\gamma$ emitting radionuclides can be detected in the human body by using positron emission tomography (PET) and single-photon emission computed tomography (SPECT), respectively. PET cameras employ opposite detectors to record simultaneous pairs of annihilation photons (511 KeV per photon), thereby detecting electronic collimation instead of mechanical collimation of incoming photons. As a result, PET sensitivity, which ranges from $10^{-11}$ to $10^{-12} \mathrm{M}$, is at least $1-2$ orders of magnitude better than the sensitivity of single-photon imaging systems $\left(10^{-10} \mathrm{M}\right){ }^{21}$

$\mathrm{Cu}$ has important roles in both cancer development and cancer growth, particularly in the processes of angiogenesis and metastasis. Malignant tissues have been characterized as having higher levels of $\mathrm{Cu}$ accumulation, and this observation is consistent with the overexpression of human copper transporter 1 (hCTR1) in cancer cells, including melanoma, breast cancer, liver cancer, lung cancer, prostate cancer, and 
glioblastoma cells. ${ }^{5,22-24}$ However, the chemical form(s) of $\mathrm{Cu}$ ions in blood serum have not been investigated. ${ }^{5}$ Increases in $\mathrm{Cu}$ uptake have been confirmed in vivo with the use of ${ }^{64} \mathrm{Cu}$ as a radiotracer. ${ }^{5}$ Thus, ${ }^{64} \mathrm{Cu}$, in combination with PET technology, provides a noninvasive method to assess various cancers.

Unlike the majority of conventional radiopharmaceuticals, ${ }^{64} \mathrm{CuCl}_{2}$ does not require complexation with peptides, antibodies, or other expensive targeting ligands. ${ }^{5}$ Moreover, ${ }^{64} \mathrm{CuCl}_{2}$ is one of the few radiocompounds that can directly serve as a probe in PET imaging of various types of cancers. Thus, the use of ${ }^{64} \mathrm{CuCl}_{2}$ can be less expensive than other methods that employ other radionuclides. Generally, ${ }^{64} \mathrm{Cu}$ is administered as a diluted solution of ${ }^{64} \mathrm{CuCl}_{2}$. Dilutions are made with saline or PBS to lower the slightly acidic nature of the $\mathrm{CuCl}_{2}$ solution to achieve a $\mathrm{pH}$ of $6-7.5$

Figure 1 shows that ${ }^{64} \mathrm{Cu}$ enters inside the cells using the enzyme $\mathrm{Ctr} 1$ and it is distributed in different organelles. Then, it enters inside the nucleus, inside DNA, using the enzyme ATOX1. There is a different behavior between normal and tumor cells. In normal cells ${ }^{64} \mathrm{Cu}$ remains in the cytoplasm while in tumor cells it enters the nucleus. In this condition, ${ }^{64} \mathrm{Cu}$ is able to produce the theranostic effect, without toxicity to normal cells.

Within the past ten years, numerous reports have been published regarding the use of ${ }^{64} \mathrm{Cu}$ as a probe in PET imaging studies of experimental mouse models of prostate, breast, colorectal, hepatoma, melanoma, fibrosarcoma, ovarian, lung, head and neck, and glioblastoma cancers. ${ }^{5}$ However, only recently has ${ }^{64} \mathrm{Cu}$ been employed as a PET imaging probe in nuclear medicine clinics for human cancers. To further explore the use of ${ }^{64} \mathrm{Cu}$ in combination with PET imaging, we have reviewed various studies that demonstrate the importance of $\mathrm{Cu}$ metabolism in maintaining good health, as well as the radiochemistry of ${ }^{64} \mathrm{Cu}$ and its applications in diagnosis and therapy.

\section{Chelators for $\mathrm{Cu}$ radionuclides}

The family of transmembrane $\mathrm{Ctr} \mathrm{Cu}$ transporter proteins is responsible for importing $\mathrm{Cu}$ into eukaryotic cells as $\mathrm{Cu}^{+1}$. This family of proteins has been identified in yeast, plants, humans, and other mammals. The $\mathrm{N}$ - and C-terminii of these proteins are characterized by multiple methionine-rich motifs and conserved histidine and cysteine residues, respectively. More recently, $\mathrm{Ctr}$ proteins have been shown to mediate the uptake of platinum-based anticancer drugs. ${ }^{25} \mathrm{Cu}$ chaperone proteins that are present in the cytosol bind soluble $\mathrm{Cu}^{1+}$ to deliver it to target proteins. It remains unclear how these chaperone proteins bind $\mathrm{Cu}^{1+}$, although it is hypothesized that direct interactions between $\mathrm{Cu}^{1+}$ and $\mathrm{Ctr}$ transporter proteins mediate the binding event. ${ }^{25}$ In order to develop ${ }^{64} \mathrm{Cu}$ radiopharmaceuticals, a chelator is necessary. $\mathrm{Cu}^{2+}$ can then be complexed with molecules and cells to form thermodynamically and kinetically stable systems. It has been very challenging to develop $\mathrm{Cu}$ chelators since there are many $\mathrm{Cu}$-chelating proteins that exist in vivo (eg, metallothionein,

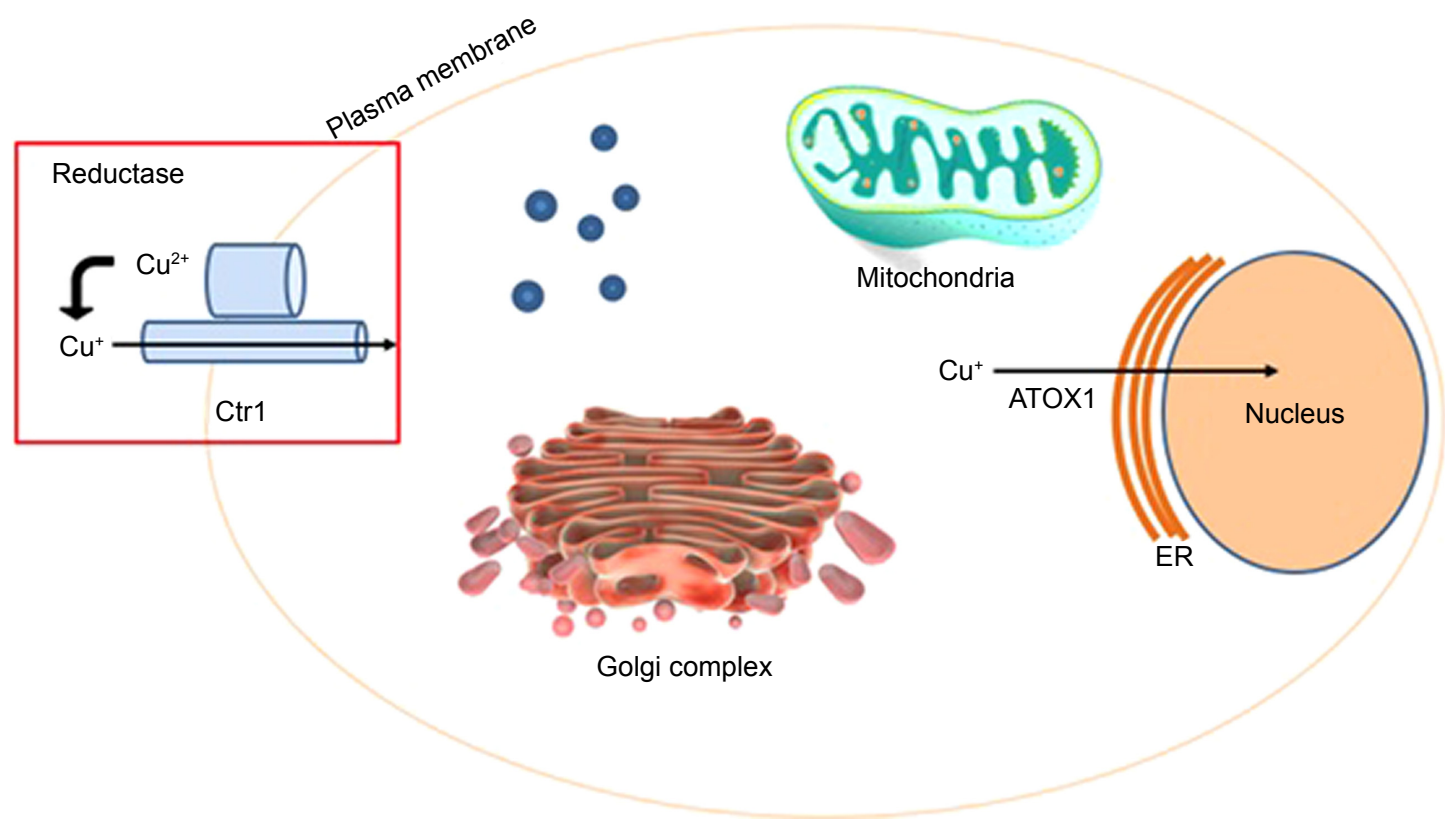

Figure I ${ }^{64} \mathrm{Cu}$ entry into the tumor cell.

Abbreviations: ATOXI, antioxidant protein; ER, endoplasmic reticulum. 
ceruloplasmin, $\mathrm{Cu}$ transporters, superoxide dismutase, and chaperone proteins), and these proteins can displace a $\mathrm{Cu}$ ion from a chelator. Among the various oxidation states that are available to $\mathrm{Cu}$, the $\mathrm{Cu}^{2+}$ form is most commonly used for ${ }^{64} \mathrm{Cu}$ radiopharmaceuticals. ${ }^{4}$

Diethylene triamine pentaacetic acid (DTPA) and EDTA, as well as their derivatives, represent commonly used acyclic $\mathrm{Cu}$ chelators. Dithiocarbamates that are typically used for chelating rhenium and technetium have also been used for chelating $\mathrm{Cu}$. Rosales et $\mathrm{al}^{26}$ reported a synthesis method for conjugating ${ }^{64} \mathrm{Cu}$-dithiocarbamatebisphosphonate to iron oxide nanoparticles. Characterization of this novel bifunctional conjugate demonstrated its ability to bind superparamagnetic iron oxide nanoparticles and ${ }^{64} \mathrm{Cu}$, which is relevant for magnetic resonance and PET imaging, respectively. The authors conducted further in vivo studies in mice and images of the conjugate in draining lymph nodes were obtained. ${ }^{26}$

Modified cyclen and cyclam are macrocycles that are commonly used to chelate $\mathrm{Cu}^{2+}$. Both 1,4,8,11-trazacyclododecane-1,4,8,11-tetraacetic acid (TETA) and 1,4,7,10-tetraazacyclododecane-1,4,7,10-tetraacetic acid (DOTA) have also been used as $\mathrm{Cu}$ chelates for PET imaging. However, the latter complexes have been reported to be unstable. ${ }^{4}$

When Pandya et al compared Cu-TETA and 1,4,8,11tetraazabicyclo[6.6.2] hexadecane (CB-TE2A), the latter was found to be more stable. ${ }^{27}$ An animal biodistribution study of the two compounds conjugated with ${ }^{64} \mathrm{Cu}$ further showed that ${ }^{64} \mathrm{Cu}$-TE2A exhibited significantly less retention in kidneys and liver after 24 hours compared with ${ }^{64} \mathrm{Cu}$-TETA. These results suggest that demetallation occurs at a slower rate in vivo. ${ }^{4,27}$

Cheng et al conducted studies in two melanoma models and greater retention and accumulation of ${ }^{64} \mathrm{Cu}-$ DOTANAPamide was observed in the livers of both models. ${ }^{28}$ The authors attribute this observation to transchelation of the conjugated compound in the liver and/or decomposition of the conjugate and release of uncoordinated ${ }^{64} \mathrm{Cu}$ into the bloodstream. The authors further suggest that chelated ${ }^{64} \mathrm{CuCl}_{2}$ would be more stable with the use of cross-bridged cyclam ligands or TETA, and its biodistribution may be improved as well.

Despite the modest stability of ${ }^{64} \mathrm{Cu}$-DOTA in vivo, it is a widely used chelator. ${ }^{4,28}$ The main reasons for this may be its commercial availability, its approval by the Federal Drug Administration, and labeling conditions. However, cyclam derivatives remain the most often used chelators due to their in vivo kinetic stability that has not been surpassed by any other chelators. Furthermore, chemical modifications of the cross-bridge or pendant arms of cyclam derivatives have resulted in improved labeling conditions without compromise of in vivo stability. ${ }^{4}$

Sarcophagine (Sar) is another well-known chelator that is able to strongly bind $\mathrm{Cu}^{2+}$ to form a highly stable complex. The in vivo stabilities of Sar ${ }^{64} \mathrm{Cu}$ complexes have been reported to be better than those of other chelators (such as DOTA), and thus, a new class of bifunctional chelators was developed based on the structure of Sar. As a result, synthesis of a cage-like hexaazamacrobicyclic Sar produced a chelator at high yields that exhibited high in vivo stability and successful radiolabeling. ${ }^{28-30}$ However, attempts to attach diamino-hexaazabicycloeicosane directly to the protein under hydrochloric acid activation have been unsuccessful due to the presence of an inert primary amine. ${ }^{28-30}$

When labeling proteins via formation of an amide bond, inactivation of biological activity is a concern. Similarly, modification of carboxylic acids or lysines near a protein's active site has the potential to interfere with binding affinity. ${ }^{28-30}$ To prepare ${ }^{64} \mathrm{Cu}$ radiopharmaceuticals, Liu et $\mathrm{al}^{29}$ have conjugated BaMalSar and $\mathrm{Mal}_{2} \mathrm{Sar}$ with cyclic $\mathrm{c}(\mathrm{RGDyC})$ via maleimide and free sulfhydryl reactions. Following the labeling of BaMalSar-RGD and $\mathrm{Mal}_{2}$ SarRGD2 with ${ }^{64} \mathrm{Cu}$, these conjugates exhibited greater uptake by tumor tissues compared with normal tissues.

The passive uptake of ${ }^{64} \mathrm{CuCl}_{2}$ by cells via pyruvaldehydebis(N4-methylthiosemicarbazone) (PTSM), a lipophilic redox-active carrier molecule, facilitates the rapid radiolabeling of cells. Moreover, PTSM exhibits greater binding affinity for divalent $[(\mathrm{Cu}$ II $)]$ compared with monovalent $\mathrm{Cu}[(\mathrm{Cu} \mathrm{I})]$. Consequently, stable $\mathrm{Cu}^{2+}-\mathrm{PTSM}$ is reduced to the more labile $\mathrm{Cu}^{1+}$-PTSM complex, thereby allowing the charged $\mathrm{Cu}^{1+}$ ion to dissociate and undergo binding by intracellular macromolecules. Meanwhile, the neutral PTSM molecule diffuses through the plasma membrane out of the cell. As a result, a concentration gradient develops across the cell membrane and $\mathrm{Cu}$-PTSM is passively taken up. In glioma cells, an influx of ${ }^{64} \mathrm{Cu}$-PTSM equilibrated after $\sim 3$ hours. ${ }^{31}$ Splenic accumulation of ${ }^{64} \mathrm{Cu}$-PTSM-labeled lymphocytes was also observed after 3 hours, although localization to the liver was the primary site. ${ }^{21}$ Furthermore, when Adonai et al obtained images following tail vein injections of labeled C6 cells, the labeled cells were found to localize to the liver and lungs of a mouse model.

During $\mathrm{Cu}$ homeostasis, $\mathrm{Cu}^{1+}$ is transported into cells via a $\mathrm{Cu}$ transporter protein, while $\mathrm{Cu}^{2+}$ is transported into cells via a divalent metal transporter protein. Upon complexation 
of the $\mathrm{Cu}$ ion to a lipophilic $\mathrm{Cu}$ chelator, such as PTSM, $\mathrm{Cu}$ can be transported into cells by passive diffusion, thereby bypassing normal cellular metabolic and excretory pathways. In normal cells, $\mathrm{Cu}^{2+}$-PTSM is reduced in mitochondria. The $\mathrm{Cu}$ molecule then enters the $\mathrm{Cu}$ metabolism pathway and remains in the cytosol bound to metallothioneins and other proteins. ${ }^{31}$

\section{Preclinical studies}

In the 1940s, early studies of Cu metabolism were conducted with radiocopper in normal and anemic rats. ${ }^{32}$ Later, blood sampling and biodistribution studies were performed with ${ }^{64} \mathrm{CuCl}_{2}$ in experimental dog models to examine the uptake of radiocopper by various tissues and organs. These results established that radiocopper remains in the plasma of blood and is also taken up by blood cells. ${ }^{33}$

Many preclinical studies of ${ }^{64} \mathrm{CuCl}_{2}$ have been conducted with various types of cancer. For example, Bahde et al administered ${ }^{64} \mathrm{Cu}$-histidine complexes to rats. In the control group, the radioactive tracer was rapidly cleared from the blood with uptake of the complexes by the liver and hepatobiliary excretion. ${ }^{34}$ Interestingly, PET imaging showed that hepatobiliary excretion of ${ }^{64} \mathrm{CuCl}_{2}$ was partially restored in the rats after they underwent transplantation of healthy hepatocytes. These data support the use of PET in monitoring the effects of hepatocyte transplantation to treat Wilson's disease. ${ }^{34}$ When ${ }^{64} \mathrm{CuCl}_{2}$ was used as a tracer in human prostate cancer xenografts, PET imaging detected high levels of hCTR1 after 24 hours, yet not after 1 hour. ${ }^{35}$ Moreover, a quantitative analysis of the PET data showed that a higher concentration of ${ }^{64} \mathrm{CuCl}_{2}$ was present in tumor tissues than in normal soft tissues. ${ }^{35}$ In a follow-up study by the same group, ${ }^{36}$ RNA interference-mediated knockdown of hCtr1 was performed to determine whether uptake of ${ }^{64} \mathrm{CuCl}_{2}$ is mediated by hCtr1 or whether ionic $\mathrm{Cu}$ nonspecifically binds to tumor tissue. After 24 hours, uptake of ${ }^{64} \mathrm{CuCl}_{2}$ by tumor cells that did not express hCtrl was significantly reduced compared to the uptake of ${ }^{64} \mathrm{CuCl}_{2}$ by control tumor cells that did express hCtr1.

When Liu et al investigated the stability and distribution of ${ }^{64} \mathrm{Cu}-\mathrm{Ba} 3 \mathrm{Sar}$ in vivo, this conjugate was found to be rapidly cleared from the kidneys. ${ }^{30}$ At 5 minutes after the tail vein injection, uptake in the liver and blood was observed, and this profile was maintained up to 30 minutes post-injection. When images were acquired 24 hours postinjection, the highest uptake was observed in the liver, which indicates the in vivo stability of ${ }^{64} \mathrm{Cu}-\mathrm{Ba} 3 \mathrm{Sar} .{ }^{30} \mathrm{Liu}$ et al also successfully tested antibodies labeled with ${ }^{64} \mathrm{CuCl}_{2}$ in
PET imaging studies of EphB4 expression in colorectal and breast cancers. ${ }^{37}$ Meanwhile, Kim et al detected an increase in the uptake of ${ }^{64} \mathrm{CuCl}_{2}$ in PET images that were collected from xenograft mice bearing MDA-MB-231 cells that were infected with a lentiviral vector that provided exogenous expression of the $h C T R 1$ gene. ${ }^{16}$ The latter results demonstrated that ${ }^{64} \mathrm{CuCl}_{2}$ could be detected up to 48 hours after its injection in vivo, and they further suggested that $h C T R 1$ could serve as a reporter gene in the use of PET with ${ }^{64} \mathrm{CuCl}_{2}$ as a probe.

Jørgensen et $\mathrm{al}^{38}$ examined the capacity of ${ }^{64} \mathrm{CuCl}_{2}$ to diagnose five different tumors, including U87MG (glioblastoma), HT29 (colorectal cancer), FaDu (head and neck cancer), A2780 (ovarian cancer), and H727 (neuroendocrine lung carcinoid). One hour after the injection of ${ }^{64} \mathrm{CuCl}_{2}$, very high uptake of the radionuclide was detected in the liver. However, 21 hours later, a marked decrease in ${ }^{64} \mathrm{CuCl}_{2}$ uptake was observed. A similar uptake profile was observed for ${ }^{64} \mathrm{CuCl}_{2}$ in bladder and kidney. Furthermore, an initial uptake of ${ }^{64} \mathrm{CuCl}_{2}$ by $4 / 5$ of the tumor types was observed, while accumulation of ${ }^{64} \mathrm{CuCl}_{2}$ was detected between 1 hour and 22 hours after injection in 3/5 of the tumor types. These results suggest that some $\mathrm{CuCl}_{2}$ is released from the liver into the blood, and then it accumulates in tumor tissue in a tumor type-dependent manner.

In a study of ${ }^{64} \mathrm{CuCl}_{2}$ as a treatment for glioblastoma (U87MG), Ferrari et al ${ }^{39}$ injected animals with ${ }^{64} \mathrm{CuCl}_{2}$ via cardiac puncture under anesthesia. The mice were subsequently divided into three groups: non-treated, treated with a single administration (SDG), and treated with a multiple-dose regimen (MDG) (with one injection administered daily for six consecutive days). In almost all of the cases, a good response was observed for the single- and multiple-dose treatments. In the SDG, a reduction in the volume of interest (VOI) was found to range from $68 \%$ to $94 \%$, and tumors completely disappeared in two of the cases. In the MDG, the VOI reduction ranged from $64 \%$ to $92 \%$, and complete disappearance of the tumor was observed in four of the cases.

Jin et $\mathrm{al}^{40}$ evaluated the therapeutic potential of ${ }^{64} \mathrm{Cu}$ cyclam-RAFT-c(-RGDfK-)4 in xenograft models of human glioblastoma cells in mice. Administration of $37 \mathrm{MBq}$ or 74 $\mathrm{MBq}$ of ${ }^{64} \mathrm{Cu}$-cyclam-RAFT-c(-RGDfK-)4 to mice carrying an $\alpha \mathrm{V} \beta 3$-positive U87MG tumor led to a dose-dependent delay in tumor growth, and this was independent of any considerable toxicities.

Qin et al ${ }^{41}$ demonstrated the potential of ${ }^{64} \mathrm{CuCl}_{2}$ to serve as a theranostic agent for malignant melanoma. Briefly, the uptake and efflux of ${ }^{64} \mathrm{CuCl}_{2}$ by two melanoma cell lines 
expressing high levels of CTR1 (A375M and B16F10) were examined. Tumor growth was found to be reduced in both of the models that received ${ }^{64} \mathrm{CuCl}_{2}$ treatment compared to the control group.

Another group of diseases that have been studied with ${ }^{64} \mathrm{Cu}$ include those related to development, aging, and function in the brain. To study changes in $\mathrm{Cu}$ metabolism with aging, various groups have used a mouse model of Wilson's disease that develops an inherited human $\mathrm{Cu}$ metabolism disorder due to a mutation present in the $A T P 7 B$ gene. ${ }^{42-44}$ Age-dependent changes in mouse brains were observed following the oral administration of ${ }^{64} \mathrm{CuCl}_{2}$ to mice. To our knowledge, these experiments were the first to demonstrate the potential of cerebral uptake of ${ }^{64} \mathrm{CuCl}_{2}$ to serve as a biomarker in noninvasive assessments of brain aging and age-related disorders.

\section{Clinical studies}

Advances in our understanding of physiological and/or pathological processes maintain an ongoing need for new radiopharmaceuticals. However, these studies are often limited by the absence of a particular radiopharmaceutical. Thus, the development of new radioactive tracers is highly relevant and it can significantly contribute to efforts to elucidate important biological phenomena.

Theranostics is a new frontier in the fields of medicine and nuclear medicine. Furthermore, the possibility of using the same compound, such as ${ }^{64} \mathrm{CuCl}_{2}$, for diagnosis and treatment opens a new era in theranostics. To date, studies of PET imaging with ${ }^{64} \mathrm{CuCl}_{2}$ as a radiotracer are in a proofof-concept phase. However, the potential of this system to be applied to personalized cancer management is extremely attractive, and thus, is an active area of research. ${ }^{5}$

The first study of ${ }^{64} \mathrm{CuCl}_{2}$ in humans was carried out by Schubert and Riezler in 1947. ${ }^{33}$ They analyzed blood samples from healthy volunteers following oral, subcutaneous, and intravenous injections of ${ }^{64} \mathrm{CuCl}_{2}$. Catalogna et $\mathrm{al}^{23}$ characterized the combined effect of ${ }^{64} \mathrm{CuCl}_{2}$ and $\mathrm{SI} 113$ on human glioblastoma multiforme cell lines with variable p53 expression. They support evidence to underline the theranostic potential of ${ }^{64} \mathrm{CuCl}_{2}$ in this tumor.

Currently, there are very few clinical cancer imaging studies with ${ }^{64} \mathrm{CuCl}_{2}$ used as a radiotracer. In addition, all of these studies have produced no carrier added (NCA)- ${ }^{64-}$ $\mathrm{CuCl}_{2}$ in a cyclotron. Capasso et $\mathrm{al}^{45}$ authored the first study of ${ }^{64} \mathrm{CuCl}_{2}$ as a PET probe with PET-CT imaging used to stage patients confirmed to have prostate cancer according to histology and MRI. ${ }^{5,45}$
While it is well recognized that $\mathrm{Cu}$ is vital for good health, overexposure to $\mathrm{Cu}$ ions can lead to a wide spectrum of side effects. One potential side effect is the production of radical species due to a Fenton-type reaction. Oxidative stress that is caused by these species can lead to downstream damage to proteins, nucleic acids, and lipids. ${ }^{5,31}$ However, cytotoxic effects have only been reported for $\mathrm{Cu}$ ions at concentrations $\geq 7.42 \mathrm{mg} / \mathrm{L}$. For PET imaging of a tumor with a reasonably good tumor-to-background ratio, only $5-10 \mathrm{mCi}$ (185-370 MBq) of ${ }^{64} \mathrm{CuCl}_{2}$ is generally administered. This clinical dose translates into few nanogram of $\mathrm{Cu}^{2+}$ ions when cyclotron-produced $\mathrm{NCA}^{64} \mathrm{Cu}$ is used. Therefore, the amount of $\mathrm{Cu}^{2+}$ ions administered in a clinical setting would not be predicted to induce cytotoxic effects. $^{5}$

The use of ${ }^{64} \mathrm{CuCl}_{2}$ for PET imaging was first reported by Panichelli et $\mathrm{al}^{46}$ for glioblastoma patients. PET-CT imaging exhibited good concurrence with MRI in this study, and no adverse effects were observed following the administration of ${ }^{64} \mathrm{CuCl}_{2}{ }^{5}$ These results support the use of ${ }^{64} \mathrm{CuCl}_{2}$ as a diagnostic agent for tumors of the central nervous system. However, to our knowledge, this is the only clinical study of ${ }^{64} \mathrm{CuCl}_{2}$ for PET imaging that has been published to date.

Recently, Righi et al ${ }^{24}$ evaluated the kinetics and dosimetry of ${ }^{64} \mathrm{CuCl}_{2}$ in 50 patients with prostate cancer. They suggest that the reported therapeutic effect of ${ }^{64} \mathrm{CuCl}_{2}$ is mainly due to Auger electron emission than to the beta radiation. Avila-Rodriguez et $\mathrm{al}^{47}$ reported the first-in-human study on biodistribution and radiation dosimetry of ${ }^{64} \mathrm{CuCl}_{2}$ in six healthy volunteers. They showed that the liver has the highest uptake, followed by intestine and pancreas while the urinary excretion is negligible. Although they are critical organs, the authors suggest that the liver, intestine, and pancreas would support therapeutic activities of up to hundreds of $\mathrm{mCi}$ (several GBq) without compromising their functions.

\section{Alzheimer's disease}

The World Health Organization has reported that among the cases of dementia, Alzheimer's accounts for $60 \%-70 \%$ of these cases. Approximately 47 million people worldwide are estimated to be suffering from dementia, and each year approximately 10 million new cases are registered. Age is considered the main risk factor for dementia, although the disease is not an inevitable consequence of aging and it does not exclusively affect older people. For example, approximately $9 \%$ of Alzheimer's patients present with symptoms prior to the age of $65 .{ }^{48,49} \mathrm{~A}$ link between cognitive impairment and lifestyle-related risk factors has been observed in cases of Alzheimer's disease, with sedentary lifestyle, unbalanced 
diet, smoking, obesity, excessive alcohol consumption, diabetes, and hypertension representing potential risk factors. Other risk factors include depression, low education level, social isolation, and cognitive inactivity. ${ }^{48,49}$

Alzheimer's is a disease that is characterized by progressive loss of synaptic activity and neuron cell death. A hallmark of Alzheimer's progression is the development of extracellular senile plaques in brain tissue. ${ }^{50}$ These plaques develop in the hippocampal and cortical regions of the brain and are composed of a 39-43 amino acid peptide derived from amyloid- $\beta$ protein precursor. The presence of this amyloid- $\beta$ peptide contributes to the disruption of trace metal homeostasis and intracellular neurofibrillary tangles. Correspondingly, copper metabolism has been found to be altered in patients with Alzheimer's, and it is hypothesized that amyloid- $\beta$ protein precursor may contribute to the mechanism of $\mathrm{Cu}$ transport. If $\mathrm{Cu}$ accumulates in extracellular plaques, this could aggravate $\mathrm{Cu}$ deficiency in neurons. ${ }^{14,50,51}$ It is also hypothesized that $\mathrm{Cu}$ metabolism has roles in Huntington's, prion, and Parkinson's diseases. ${ }^{14}$

Uptake, distribution, and removal of $\mathrm{Cu}$ from the brain are regulated by enzymes and proteins that specifically bind or transport $\mathrm{Cu}$. When $\mathrm{Cu}$ is abnormally distributed in the brain, when it is inaccurately bound, or when it is present at higher or lower levels, neurodegenerative disorders may develop. Premortem studies of Alzheimer's disease that used $\mathrm{Cu}$ radionuclides supported the role of $\mathrm{Cu}$ in Alzheimer's disease pathology. ${ }^{12}$

To date, the mechanistic details of a possible role of $\mathrm{Cu}$ in neurological pathologies remain unclear. Furthermore, to our knowledge, there is currently no clinical data available regarding the use of ${ }^{64} \mathrm{CuCl}_{2}$ in Alzheimer's disease. However, studies of $\mathrm{Cu}$ metabolism among the large population of affected patients is an active area of research. ${ }^{12}$

\section{Hypoxia in tumor tissue}

Carcinogenesis in solid tumors is characterized by a rapid proliferation of tumor cells that outpaces the process of angiogenesis. As a result, a hypoxic region is often observed in cells that are at a distance from blood vessels (generally $>100$ $\mathrm{mm}$ ) due to inefficient tumor vascularization. ${ }^{52}$ Consequently, hypoxia is often considered a hallmark of cancer, and in a number of tumor types, it is a predictor of tumor progression, resistance to therapeutic agents, and poor prognosis via multiple mechanisms. ${ }^{53}$ Biochemists define hypoxia as limited electron transport of $\mathrm{O}_{2}^{-}$in mitochondria, while physiologists define hypoxia as a reduction in $\mathrm{O}_{2}$ availability due to decreased $\mathrm{O}_{2}$ partial pressure. The clinical aspect of hypoxia involves limited oxygen delivery to aerobic stromal and neoplastic cells, with the partial pressure for oxygen in several tumor types being $<5 \mathrm{mmHg}$ vs $40-60 \mathrm{mmHg}$ in normal tissues. ${ }^{54}$

Over the past ten years, hypoxia has been shown to affect gene expression and alter tumor malignancy to promote a more aggressive phenotype. Thus, it has been difficult to treat hypoxic cancers with cytotoxic chemotherapy, photodynamic therapy, or radiation. To counteract the effects of hypoxia, radiation-sensitizing drugs and hyperbaric oxygen have been applied. However, the application of hypoxia-specific cytotoxins has been more encouraging. To evaluate hypoxiadirected therapies in clinical trials, noninvasive detection and monitoring of hypoxia are needed. In addition, the ability to image hypoxia could help identify patients who would most benefit hypoxia-targeted therapies. ${ }^{55}$

A number of promising PET radiopharmaceuticals have been tested for their ability to measure $\mathrm{pO}_{2}$. $\left[{ }^{18} \mathrm{~F}\right]$-fluoromisonidazole is the classical reference for nitroimidazole compounds to date and has been used to measure $\mathrm{pO}_{2}$. ATSM [diacetyl-bis(N4-methylthiosemicarbazone)] has also been used to image hypoxia and can be labeled with different $\mathrm{Cu}$ isotopes $\left(\mathrm{eg},{ }^{60 / 61 / 62 / 64} \mathrm{Cu}\right)$. When the metabolism and pharmacology of ATSM-Cu complexes are the same and are independent of the isotope used, then the physical properties of the isotopes used should be considered..$^{52}$ The first human use of ${ }^{64} \mathrm{Cu}$-ATSM was published in 2000 in a cohort of lung cancer, and all patients presented with positive exams.

For PET imaging of hypoxia, an injection of $925 \mathrm{MBq}$ of ${ }^{64} \mathrm{Cu}$-ATSM has been performed. For a diagnostic protocol, this is a relatively high dosimetric value. However, it is consistent with liver radiation detected during multidetector CT scans of the abdomen (11.5 mSv for a tissue weighting factor of 0.04 ) and the magnitude of total body dosimetry observed for thallium-201 during cardiac imaging of stress and rest conditions. ${ }^{56}$

In clinical PET studies with ${ }^{64} \mathrm{Cu}$-ATSM, a disparity between normoxic and hypoxic tissues has been observed 10-15 minute post-injection, consistent with radio-/chemoresistance findings for various tumors, including lung, rectal, and cervical carcinomas. ${ }^{52}$ Imaging uniformity may be related to the site of uptake (eg, by mitochondria or in the cytosol) or the biochemical pathways involved (eg, glycolysis or oxidative pathways). Furthermore, cellular accumulation of ${ }^{64} \mathrm{Cu}$-ATSM may be related to cancer cell phenotypes, and this could affect patient outcome..$^{52}$

Severe and chronic hypoxia can lead to a decrease in intracellular reactive oxygen species and reduced oxidative 
phosphorylation in mitochondria. While it has been observed that uptake of Cu-ATSM is enhanced under these conditions, it remains unclear whether there is a direct correlation between these conditions and Cu-ATSM uptake. However, clinical studies have demonstrated that uptake of $\mathrm{Cu}$-ATSM was associated with a worse prognosis in cases involving cancer of the lung, uterine cervix, and rectum. ${ }^{54}$

The ability to produce and deliver ${ }^{64} \mathrm{Cu}$ has been established by several companies. For example, ACOM (Italy), MDS Nordion (Canada), IBA Molecular (US and Europe), IsoTrace (US), and Trace Life Sciences (US) currently sell ${ }^{64} \mathrm{CuCl}_{2}$ for the preparation of radiopharmaceuticals. In particular, ${ }^{64} \mathrm{Cu}$-ATSM is a preferred reagent for PET imaging of tumor hypoxia based on the simple method for its synthesis, its straightforward quantification, and its more rapid clearance rate from normoxic tissue that facilitates a short period of time between its injection and imaging. 54,55

\section{Neuroendocrine tumors (NETs)}

It remains challenging to diagnose NETs due to their highly variable symptoms, their relatively small size, and their ability to develop anywhere in the body. Generally, there is a 5-7 year delay between the initial presentation of symptoms and the diagnosis of patients with NETs. Unfortunately, during this time, $20 \%-50 \%$ of patients will develop metastatic disease. Therefore, there is a great need to obtain an early diagnosis with a sensitive and easily accessible diagnostic imaging method. Sensitive imaging modalities would also be useful for long-term surveillance of NETs in order to detect progression/recurrence in its early stages and modify treatment strategy accordingly. ${ }^{57}$

Overexpression of somatostatin receptors distinguishes NETs from other tumors. ${ }^{57-59}$ Consequently, analogs of somatostatin receptors have been used both for imaging and pharmacological treatment. In addition, radiolabeling of peptides has been used to provide receptor-targeted radionuclide therapy. ${ }^{59}$

Pfeifer et $\mathrm{al}^{58}$ conducted a study in which patients with a history of NETs underwent SPECT/CT with ${ }^{111}$ In-DTPAoctreotide and PET/CT with ${ }^{64} \mathrm{Cu}$-labeled-(DOTATATE). The latter produced images with high spatial resolution and excellent quality. ${ }^{64} \mathrm{Cu}$-DOTATATE PET also detected additional lesions in 6/14 patients. In five of these patients, the lesions were localized to organ systems and organs that had not previously been characterized as possible sites of metastasis.

Similarly, in a prospective study of ${ }^{64} \mathrm{Cu}$-DOTATATE and ${ }^{68} \mathrm{Ga}$-labeled-(DOTATOC) that was conducted by
Johnbeck et al, ${ }^{57}$ the former exhibited a markedly improved lesion detection rate in NET patients $(n=59)$. Furthermore, additional lesions were detected by ${ }^{64} \mathrm{Cu}$-DOTATATE during the follow-up period, and most of these lesions were true positives. This result is attributed to the lower detection range of ${ }^{64} \mathrm{Cu}$ compared to ${ }^{68} \mathrm{Ga}$. In addition, the shelf life of ${ }^{64} \mathrm{Cu}$ is greater than 24 hours and it has a flexible scan window (eg, $>3$ hour), which makes ${ }^{64} \mathrm{Cu}$-DOTATATE very attractive for use in a clinical routine. Further studies are needed to confirm whether reliable detection of NETs translates into better patient management and improved outcome.

\section{${ }^{64} \mathrm{Cu}$-labeled antibodies}

Accumulating evidence supports a role for ephrin type B receptor $4(\mathrm{EphB} 4)$ in the progression of various cancers. In one of these studies, ${ }^{64} \mathrm{Cu}$-labeled anti-EphB4 antibodies (hAb47 and hAb131) were used to characterize the distribution of EphB4 both in vitro and in vivo in models of breast and colorectal cancers. ${ }^{37}$ This approach could facilitate evaluations of dose optimization, pharmacokinetics, dose interval, and tumor-targeting efficacy of hAb47 and hAb131 antibodybased cancer therapeutics. Furthermore, these probes could be applied to other cancer types that overexpress EphB4.

The first Phase I/II clinical study of a ${ }^{64} \mathrm{Cu}$-labeled antibody was conducted by Philpott et al. ${ }^{60}$ In this study, uptake of the monoclonal antibody, ${ }^{64} \mathrm{Cu}$-BAT-2IT-1A3, and ${ }^{18} \mathrm{~F}$-FDG was detected in patients that were suspected to have metastatic, or advanced primary, colorectal cancer $(n=36)$. ${ }^{64} \mathrm{Cu}$-BAT-2IT-1A3 exhibited greater specificity in detecting colorectal tumors compared with ${ }^{18} \mathrm{~F}$-FDG. The therapeutic potential of ${ }^{64} \mathrm{Cu}$-BAT-2IT-1A3 and ${ }^{67} \mathrm{Cu}$ - BAT-2IT-1A3 was also evaluated in additional preclinical studies. Taken together, these results demonstrate that ${ }^{64} \mathrm{Cu}$ should be further developed as a radioimmunotherapy agent. ${ }^{37,60,61}$

\section{${ }^{64}$ Cu-prostate-specific membrane antigen (PSMA)}

In the US, prostate cancer is the second leading cause of cancer-related death and the most common cancer diagnosed in men. ${ }^{62}$ Radiation or surgery is typically the first line of treatment. However, tumor recurrence frequently occurs and it is difficult to detect in its early stages since CT and MRI imaging frequently provide unsatisfactory specificity and sensitivity ${ }^{63,64}$ Hence, there is an ongoing need to develop better imaging techniques for prostate cancer. PSMA has been identified as a promising target for endoradiotherapy and scintigraphic imaging of prostate cancer. ${ }^{63,64}$ This type II transmembrane protein is also not only overexpressed in 
androgen-dependent and androgen-independent advanced and metastatic prostate cancer, but also in schwannoma, in the tumor neovasculature of many solid tumors, and in certain subtypes of bladder carcinoma. ${ }^{63}$ To date, the function of PSMA remains unknown, although it has been observed to relocalize from the apical membrane to the luminal surface of ducts during dysplastic and neoplastic transformations of prostate tissues. ${ }^{63}$

PSMA-617 was the first ${ }^{64} \mathrm{Cu}$-labeled ligand to be used for PET imaging in a clinical study. This study included 29 patients (mean age, 71 years) from two centers in Germany and Austria. ${ }^{64}$ The patients received an injection of ${ }^{64} \mathrm{Cu}$ PSMA-617 (synthesized by ACOM, Italy) and no pharmacological or adverse effects were subsequently observed. The images obtained showed a high lesion contrast with a reasonable effective dose compared to the images obtained with administration of ${ }^{18} \mathrm{~F}$-choline PET/CT or ${ }^{68} \mathrm{Ga}$-PSMA PET/CT. Moreover, all of the patients with local disease that was confirmed histologically were identified with ${ }^{64} \mathrm{Cu}-$ PSMA-617 PET imaging. There were two cases of suspected lymph node metastasis that were confirmed by MRI or they had been suspected based on previous PET imaging that employed different radiopharmaceuticals. These results support the labeling of PSMA ligands with radionuclides that have a longer half-life (eg, ${ }^{64} \mathrm{Cu}$ ) for use by PET centers that otherwise lack radiochemistry facilities and ${ }^{68} \mathrm{Ga}$ generators (satellite concept). ${ }^{64}$

The studies highlighted in this review demonstrate that ${ }^{64} \mathrm{CuCl}_{2}$ is a unique radiopharmaceutical with physiological properties that are compatible with its use as a diagnostic and therapeutic agent. To date, this dual capacity has only previously been described for radioiodine. Thus, ${ }^{64} \mathrm{CuCl}_{2}$ represents a revolutionary radiopharmaceutical for theranostic purposes and its complex chemistry is outweighed by its imaging advantages compared with other radiopharmaceuticals, such as ${ }^{68} \mathrm{Ga}$ (short half-life [68 minutes] and lower resolution due to higher positron energy). Furthermore, based on the initial results obtained with use of ${ }^{64} \mathrm{Cu}$ as a therapeutic, it is anticipated that further applications of ${ }^{64} \mathrm{CuCl}_{2}$ will continue this new era in the field of theranostics.

\section{Acknowledgment}

This work was supported by the National Council for Scientific and Technological Development (CNPq) and International Atomic Energy Agency (IAEA), CRP F22067.

\section{Disclosure}

The authors report no conflicts of interest in this work.

\section{References}

1. IAEA Radioisotopes and radiopharmaceuticals Reports No.1. Cyclotron produced radionuclides: Emerging positron emitters for medical applications: 64Cu and 124I. 2016. Available from: https://www-pub. iaea.org/books/IAEABooks/10791/Cyclotron-Produced-Radionuclides-Emerging-Positron-Emitters-for-Medical-Applications-64Cuand-124I.

2. Osredkar J, Sustar N. Copper and zinc, biological role and significance of copper/zinc imbalance. J Clin Toxicol. 2011;S3:001. Accessed July 3, 2018.

3. Chellan P, Sadler PJ. The elements of life and medicines. Philosophical Transactions of the Royal Society A: Mathematical, Physical and Engineering Sciences. 2015;373(2037):20140182.

4. Cai Z, Anderson CJ. Chelators for copper radionuclides in positron emission tomography radiopharmaceuticals. J Labelled Comp Radiopharm. 2014;57(4):224-230.

5. Chakravarty R, Chakraborty S, Dash A. ${ }^{64} \mathrm{Cu}^{2+}$ Ions as PET Probe: An Emerging Paradigm in Molecular Imaging of Cancer. Mol Pharm. 2016;13(11):3601-3612.

6. Mercer JF, Camakaris J. Copper comes of age in Melbourne. Metallomics. 2016;8(9):816-823.

7. Burlando B, Evangelisti V, Dondero F, Pons G, Camakaris J, Viarengo A. Occurrence of Cu-ATPase in Dictyostelium: possible role in resistance to copper. Biochem Biophys Res Commun. 2002;291(3):476-483.

8. Montes S, Rivera-Mancia S, Diaz-Ruiz A, Tristan-Lopez L, Rios C. Copper and copper proteins in Parkinson's disease. Oxid Med Cell Longev. 2014;2014:147251.

9. Boll MC, Alcaraz-Zubeldia M, Montes S, Rios C. Free copper, ferroxidase and SOD1 activities, lipid peroxidation and $\mathrm{NO}_{(\mathrm{x})}$ content in the CSF. A different marker profile in four neurodegenerative diseases. Neurochem Res. 2008;33(9):1717-1723.

10. Eum WS, Kang JH. Release of copper ions from the familial amyotrophic lateral sclerosis-associated $\mathrm{Cu}, \mathrm{Zn}$-superoxide dismutase mutants. Mol Cells. 1998;9(1):110-114.

11. Bellingham SA, Lahiri DK, Maloney B, La Fontaine S, Multhaup G, Camakaris J. Copper depletion down-regulates expression of the Alzheimer's disease amyloid-beta precursor protein gene. J Biol Chem. 2004;279(19):20378-20386.

12. Hueting R. Radiocopper for the imaging of copper metabolism. J Labelled Comp Radiopharm. 2014;57(4):231-238.

13. Mercer JF, Llanos RM. Molecular and cellular aspects of copper transport in developing mammals. J Nutr. 2003;133(5 Suppl 1): 1481S-1484S.

14. Camakaris J, Voskoboinik I, Mercer JF. Molecular mechanisms of copper homeostasis. Biochem Biophys Res Commun. 1999;261(2):225-232.

15. Camakaris J, Petris MJ, Bailey L, et al. Gene amplification of the Menkes (MNK; ATP7A) P-type ATPase gene of CHO cells is associated with copper resistance and enhanced copper efflux. Hum Mol Genet. 1995;4(11):2117-2123.

16. Kim KI, Jang SJ, Park JH, et al. Detection of increased $64 \mathrm{Cu}$ uptake by human copper transporter 1 gene overexpression using PET with $64 \mathrm{CuCl} 2$ in human breast cancer xenograft model. J Nucl Med. 2014; 55(10):1692-1698.

17. Lee J, Peña MM, Nose Y, Thiele DJ. Biochemical characterization of the human copper transporter Ctr1. J Biol Chem. 2002;277(6): $4380-4387$.

18. Jalilian AR, Rowshanfarzad P, Sabet M. Preparation of $\left[{ }^{61} \mathrm{Cu}\right]$ pyruvaldehyde-bis (N4-methylthiosemicarbazone) complex as a possible PET radiopharmaceutical. Radiochim Acta. 2006;94:113-117.

19. Bhargava KK, Gupta RK, Nichols KJ, Palestro CJ. In vitro human leukocyte labeling with ${ }^{64} \mathrm{Cu}$ : an intraindividual comparison with ${ }^{111}$ In-oxine and ${ }^{18}$ F-FDG. Nucl Med Biol. 2009;36(5):545-549.

20. Zhou M, Zhao J, Tian M, et al. Radio-photothermal therapy mediated by a single compartment nanoplatform depletes tumor initiating cells and reduces lung metastasis in the orthotopic 4T1 breast tumor model. Nanoscale. 2015;7(46):19438-19447. 
21. Adonai N, Adonai N, Nguyen KN, et al. Ex vivo cell labeling with 64Cu-pyruvaldehyde-bis(N4-methylthiosemicarbazone) for imaging cell trafficking in mice with positron-emission tomography. Proc Natl Acad Sci U S A. 2002;99(5):3030-3035.

22. Jiang $\mathrm{L}, \mathrm{Tu} \mathrm{Y}, \mathrm{Hu} \mathrm{X}$. Pilot study of ${ }^{64} \mathrm{Cu}(\mathrm{I})$ for PET imaging of melanoma. Sci Rep. 2017;31(7):2574.

23. Catalogna G, Talarico C, Dattilo V, et al. The SGK1 kinase inhibitor SI1 13 sensitizes theranostic effects of the $64 \mathrm{CuCl} 2$ in human glioblastoma multiforme cells. Cell Physiol Biochem. 2017;43(1):108-119.

24. Righi S, Ugolini M, Bottoni G. Biokinetic and dosimetric aspects of ${ }^{64} \mathrm{CuCl}_{2}$ in human prostate cancer: possible theranostic implications. EJNMMI Res. 2018;8(1):18.

25. Boal AK, Rosenzweig AC. Structural biology of copper trafficking. Chem Rev. 2009;109(10):4760-4779.

26. Torres Martin de Rosales R, Tavaré R, Paul RL, et al. Synthesis of $64 \mathrm{Cu}(\mathrm{II})$-bis(dithiocarbamatebisphosphonate) and its conjugation with superparamagnetic iron oxide nanoparticles: in vivo evaluation as dual-modality PET-MRI agent. Angew Chem Int Ed Engl. 2011;50(24): 5509-5513.

27. Pandya DN, Kim JY, Park JC, et al. Revival of TE2A; a better chelate for Cu(II) ions than TETA? Chem Commun. 2010;46(20):3517-3519.

28. Cheng Z, Xiong Z, Subbarayan M, Chen X, Gambhir SS. ${ }^{64} \mathrm{Cu}-$ labeled alpha-melanocyte-stimulating hormone analog for microPET imaging of melanocortin 1 receptor expression. Bioconjug Chem. 2007;18(3):765-772.

29. Liu S, Li D, Huang CW. The efficient synthesis and biological evaluation of novel bi-functionalized sarcophagine for ${ }^{64} \mathrm{cu}$ radiopharmaceuticals. Theranostics. 2012;2(6):589-596.

30. Liu S, Li Z, Conti PS. Development of multi-functional chelators based on sarcophagine cages. Molecules. 2014;19(4):4246-4255.

31. Huang J, Lee CC, Sutcliffe JL, Cherry SR, Tarantal AF. Radiolabeling rhesus monkey $\mathrm{CD} 34^{+}$hematopoietic and mesenchymal stem cells with ${ }^{64} \mathrm{Cu}$-pyruvaldehyde-bis(N4-methylthiosemicarbazone) for microPET imaging. Mol Imaging. 2008;7(1):7290.

32. Schultze MO, Simmons SJ. The use of radioactive copper in studies on nutritional anemia of rats. J Biol Chem. 1942;142:97-106.

33. Schubert G, Riezler W. Indicator-Untersuchungen mit Radiokupfer beim Menschen; die Absorption parenteral und enteral zugeführter Kupferdosen, zugleich Untersuchungen über die Kreislaufzeit [Indicator examinations with radio-ligands in humans; the absorption of parenterally and enterally supplied copper doses, at the same time studies on the circulation time]. Klin Wochenschr. 1947;24:304-306. German.

34. Bahde R, Kapoor S, Bhargava KK, Schilsky ML, Palestro CJ, Gupta S. PET with $64 \mathrm{Cu}$-histidine for noninvasive diagnosis of biliary copper excretion in Long-Evans cinnamon rat model of Wilson disease. J Nucl Med. 2012;53(6):961-968.

35. Peng F, Lu X, Janisse J, Muzik O, Shields AF. PET of human prostate cancer xenografts in mice with increased uptake of $64 \mathrm{CuCl} 2$. J Nucl Med. 2006;47(10):1649-1652.

36. Cai H, Wu JS, Muzik O, Hsieh JT, Lee RJ, Peng F. Reduced $64 \mathrm{Cu}$ uptake and tumor growth inhibition by knockdown of human copper transporter 1 in xenograft mouse model of prostate cancer. $J$ Nucl Med. 2014;55(4):622-628.

37. Liu S, Li D, Park R, et al. PET imaging of colorectal and breast cancer by targeting EphB4 receptor with 64Cu-labeled hAb47 and hAb131 antibodies. J Nucl Med. 2013;54(7):1094-1100.

38. Jørgensen JT, Persson M, Madsen J, Kjær A. High tumor uptake of (64) $\mathrm{Cu}$ : implications for molecular imaging of tumor characteristics with copper-based PET tracers. Nucl Med Biol. 2013;40(3):345-350.

39. Ferrari C, Asabella AN, Villano C, et al. Copper-64 Dichloride as Theranostic Agent for Glioblastoma Multiforme: A Preclinical Study. Biomed Res Int. 2015;2015:1-6.

40. Jin $Z H$, Furukawa $T$, Degardin $M$, et al. $\alpha V \beta 3$ Integrin-Targeted Radionuclide Therapy with 64Cu-cyclam-RAFT-c(-RGDfK-)4. Mol Cancer Ther. 2016;15(9):2076-2085.

41. Qin C, Liu H, Chen K, et al. Theranostics of malignant melanoma with 64CuCl2. J Nucl Med. 2014;55(5):812-817.
42. Xie F, Xi Y, Pascual JM, Muzik O, Peng F. Age-dependent changes of cerebral copper metabolism in Atp7b-/-knockout mouse model of Wilson's disease by $\left[{ }^{64} \mathrm{Cu}\right] \mathrm{CuCl}_{2}-\mathrm{PET} / \mathrm{CT}$. Metab Brain Dis. 2017;32(3): 717-726.

43. Peng F, Lutsenko S, Sun X, Muzik O. Imaging copper metabolism imbalance in Atp7b (-/-) knockout mouse model of Wilson's disease with PET-CT and orally administered 64CuCl2. Mol Imaging Biol. 2012;14(5):600-607.

44. Peng F, Xie F, Muzik O. Alteration of Copper Fluxes in Brain Aging: A Longitudinal Study in Rodent Using ${ }^{64} \mathrm{CuCl}_{2}-\mathrm{PET} / \mathrm{CT}$. Aging Dis. 2018;9(1):109-118.

45. Capasso E, Durzu S, Piras S, et al. Role of (64)CuCl 2 PET/CT in staging of prostate cancer. Ann Nucl Med. 2015;29(6):482-488.

46. Panichelli $\mathrm{P}$, Villano $\mathrm{C}$, Cistaro A, et al. Imaging of brain tumors with copper-64 chloride: early experience and results. Cancer Biother Radiopharm. 2016;31(5):159-167.

47. Avila-Rodriguez MA, Rios C, Carrasco-Hernandez J, et al. Biodistribution and radiation dosimetry of $\left[{ }^{64} \mathrm{Cu}\right]$ copper dichloride: first-in-human study in healthy volunteers. EJNMMI Res. 2017;7(1):98.

48. World Health Organization (WHO) Dementia: a public health priority. Geneva: World Health Organization - Alzeheimer's Disease International; 2012.

49. Alzheimer's Disease International. The global voice on dementia. Policy brief for heads of government. The global impact of dementia 2013-2050. 2013.

50. Fodero-Tavoletti MT, Villemagne VL, Paterson BM, et al. Bis(thiosemicarbazonato) $\mathrm{Cu}-64$ complexes for positron emission tomography imaging of Alzheimer's disease. J Alzheimers Dis. 2010; 20(1):49-55.

51. Acevedo KM, Hung YH, Dalziel AH, et al. Copper promotes the trafficking of the amyloid precursor protein. J Biol Chem. 2011;286(10): 8252-8262.

52. Bourgeois M, Rajerison H, Guerard F, et al. Contribution of [64Cu]ATSM PET in molecular imaging of tumour hypoxia compared to classical [18F]-MISO - a selected review. Nucl Med Rev Cent East Eur. 2011;14(2):90-95.

53. Hicks KO, Siim BG, Jaiswal JK, et al. Pharmacokinetic/pharmacodynamic modeling identifies SN30000 and SN29751 as tirapazamine analogues with improved tissue penetration and hypoxic cell killing in tumors. Clin Cancer Res. 2010;16(20):4946-4957.

54. Colombié M, Gouard S, Frindel M, et al. Focus on the controversial aspects of 64Cu-ATSM in tumoral hypoxia mapping by PET imaging. Front Med. 2015;2:58.

55. Padhani AR, Krohn KA, Lewis JS, Alber M. Imaging oxygenation of human tumours. Eur Radiol. 2007;17(4):861-872.

56. Lewis JS, Laforest R, Dehdashti F, Grigsby PW, Welch MJ, Siegel BA. An imaging comparison of 64Cu-ATSM and 60Cu-ATSM in cancer of the uterine cervix. $J$ Nucl Med. 2008;49(7):1177-1182.

57. Johnbeck CB, Knigge U, Loft A, et al. Head-to-head comparison of ${ }^{64} \mathrm{Cu}$-DOTATATE and ${ }^{68} \mathrm{Ga}$-DOTATOC PET/CT: a prospective study of 59 patients with neuroendocrine tumors. $J$ Nucl Med. 2017; 58(3):451-457.

58. Pfeifer A, Knigge U, Mortensen J, et al. Clinical PET of neuroendocrine tumors using 64Cu-DOTATATE: first-in-humans study. J Nucl Med. 2012;53(8):1207-1215.

59. Johnbeck CB, Knigge U, Kjær A. PET tracers for somatostatin receptor imaging of neuroendocrine tumors: current status and review of the literature. Future Oncol. 2014;10(14):2259-2277.

60. Philpott GW, Schwarz SW, Anderson CJ, et al. RadioimmunoPET: detection of colorectal carcinoma with positron-emitting copper-64-labeled monoclonal antibody. J Nucl Med. 1995;36(10): $1818-1824$.

61. Holland JP, Williamson MJ, Lewis JS. Unconventional nuclides for radiopharmaceuticals. Mol Imaging. 2010;9(1):7290.

62. Mease RC, Foss CA, Pomper MG. PET imaging in prostate cancer: focus on prostate-specific membrane antigen. Curr Top Med Chem. 2013; 13(8):951-962. 
63. Afshar-Oromieh A, Hetzheim H, Kratochwil C, et al. The theranostic PSMA ligand PSMA-617 in the diagnosis of prostate cancer by PET/ CT: biodistribution in humans, radiation dosimetry, and first evaluation of tumor lesions. J Nucl Med. 2015;56(11):1697-1705.
64. Grubmüller B, Baum RP, Capasso E, et al. ${ }^{64} \mathrm{Cu}-\mathrm{PSMA}-617$ PET/CT imaging of prostate adenocarcinoma: first in-human studies. Cancer Biother Radiopharm. 2016;31(8):277-286.

\section{Publish your work in this journal}

Drug Design, Development and Therapy is an international, peerreviewed open-access journal that spans the spectrum of drug design and development through to clinical applications. Clinical outcomes, patient safety, and programs for the development and effective, safe, and sustained use of medicines are the features of the journal, which has also been accepted for indexing on PubMed Central. The manuscript management system is completely online and includes a very quick and fair peer-review system, which is all easy to use. Visit http://www.dovepress.com/testimonials.php to read real quotes from published authors.

Submit your manuscript here: http://www.dovepress.com/drug-design-development-and-therapy-journal 